\title{
Zinc bis(allyldithiocarbamate) for highly refractive and flexible materials via the thiol-ene reaction
}

\author{
Shintaro Nagayama and Bungo Ochiai
}

Novel zinc bis(allyldithiocarbamate) $\left(\mathrm{Zn}(\mathrm{ADTC})_{2}\right)$ complexes, prepared from allylamines, carbon disulfide and zinc nitrate, were applied for the synthesis of highly refractive materials. Transparent and flexible films were prepared by the thiol-ene reaction of $\mathrm{Zn}(\mathrm{ADTC})_{2}$ derivatives with a tetrathiol and a diacrylate initiated with Irgacure 651. The refractive index of the films increased with the feed ratio of the $\mathrm{Zn}(\mathrm{ADTC})_{2}$ derivatives. The calculated $n_{\mathrm{D}}$ values of the components originating from the two $\mathrm{Zn}(\mathrm{ADTC})_{2}$ complexes were 1.71 and 1.67 .

Polymer Journal (2016) 48, 1059-1064; doi:10.1038/pj.2016.70; published online 10 August 2016

\section{INTRODUCTION}

Organic-inorganic hybrid structures have been a primary focus in developing effective components for optical materials given the excellent refractive properties that some of these materials exhibit. ${ }^{1-20}$ Moreover, such a hybrid structure has the potential to combine desirable properties that cannot be obtained in non-hybrid systems - for example, taking the good refractivity of an inorganic component and merging it with the processability and flexibility of an organic one, which may find applications in flexible devices, waveguides and optical adhesives. However, increasing the refractive index without the loss of flexibility is still a great challenge owing to the contradiction between the high density for refractivity and low density for flexibility.

There are two ways to prepare refractive hybrid materials. The first strategy involves the incorporation of inorganic materials, like nanoparticles, into organic polymers, which can also lend improved mechanical and electrical properties. ${ }^{2-5,10}$ Metal oxides and sulfides, such as titanium oxide and lead to sulfide, are typically used this way, yielding transparent products with high-refractive indices. However, the surface structure and size of the constituents must be precisely tuned, depending on the organic polymers used, to attain homogeneous dispersion.

The other commonly used strategy involves the polymerization of organic-inorganic hybrid monomers, such as organometallics bearing polymerizable functional groups. Applying the sol-gel method to alkoxysilyl monomers with polymerizable groups is, in fact, the most common preparation method, and has the added benefit of being environmentally friendly. ${ }^{16-18,20}$ Although this method has been industrialized for the production of thin coatings, it has some disadvantages, such as low throughput and shrinkage during the drying processes, which results in cracks and size inconsistencies.
The second strategy also includes other approaches that rely on various polymerization methods. For example, hybrid polymers with high $n_{\mathrm{D}}$ values in the range of 1.590-1.703 and a high transparency at $633 \mathrm{~nm}$ were obtained via the thiol-ene reaction of multi-vinyl compounds of $\mathrm{Si}, \mathrm{Ge}$ and $\mathrm{Sn} .{ }^{8}$ However, in spite of the excellent refractive indices and good mechanical properties exhibited, this method requires expensive monomers and the Sn monomer that achieves high $n_{\mathrm{D}}$ values is toxic. Recently, Lee et al., ${ }^{21}$ reported an Hf monomer with tetraacrylate moieties (HCA), a refractive monomer that can be copolymerized with acrylates by UV irradiation to introduce transparent films. The $n_{\mathrm{D}}$ value of the films increased up to $\sim 1.65$ as the HCA feed ratio increased. However, the product probably has a disadvantage of low water tolerance owing to the ionic bond of the metal carboxylate, although this was not examined, in a similar manner to previously reported polymers of $\mathrm{Zr}^{22}$ and $\mathrm{Zn}^{23}$ -based carboxylate monomers.

In contrast to these conventional approaches, that directly connect the organic and inorganic moieties or employ oxygen as a bridge our group is focusing on using $S$, given its excellent affinity toward both of these types of moieties, ${ }^{24-28}$ which combined with this element's high atomic refraction, are major advantages for the development of refractive materials. ${ }^{29-33}$ For example, we recently reported organic $\mathrm{S}-\mathrm{Zn}$ hybrid materials prepared via the polycondensation of $\mathrm{Zn}(\mathrm{OAc})_{2}$ and a trithiol. ${ }^{33}$ The nanosized product can homogeneously disperse in poly(methyl methacrylate) and provide improved refractive indices. However, the long C18 alkyl chains needed for sufficient solubility limited improvements to the refractive index of the polymer, which remained at the calculated $n_{\mathrm{D}}$ value of 1.58 .

To overcome this problem, we designed new hybrid monomers, zinc bis $\left(\mathrm{N}\right.$-allyldithiocarbamate) $\left(\mathrm{Zn}(\mathrm{ADTC})_{2}\right)$ derivatives, that were prepared from allylamines, carbon disulfide and zinc salts. Although zinc alkyldithiocarbamates are usually used in vulcanization 
accelerators $^{28}$ and as precursors to metal sulfides, ${ }^{27}$ they have not, to the best of our knowledge, previously been used in the production of optical materials. We employed the thiol-ene reaction as the curing method, as the sulfide linkages produced in this reaction are typically flexible. ${ }^{34}$ Furthermore, it is a fast reaction that occurs under ambient conditions and with low-curing shrinkage, all of which are suitable features for optical films ${ }^{30,34-38}$ for flexible devices and optical adhesives. ${ }^{39-43}$

\section{EXPERIMENTAL PROCEDURE}

\section{Materials and methods}

Diallylamine (Tokyo Chemical Industry, Tokyo, Japan, >99\%) and allylamine (Tokyo Chemical Industry, >99\%) were dried with sodium hydroxide and distilled under a nitrogen atmosphere. Irgacure 651 (Ciba Specialty Chemicals, Basel, Switzerland), zinc nitrate hexahydrate (Sigma-Aldrich, St Louis, MO, USA, $>95 \%$ ), pentaerythritol tetrakis(3-mercaptopropionate) (PTM) (SigmaAldrich, >95\%), propionaldehyde (Tokyo Chemical Industry, >99\%) and sodium borohydride (Kanto Chemical, Tokyo, Japan, >99\%) were used as received. Allylpropylamine was obtained via the $\mathrm{NaBH}_{4}$ reduction of the imine prepared from allylamine and propionaldehyde. ${ }^{42}$ Carbon disulfide (Kanto Chemical, >99\%) was dried sequentially with $\mathrm{CaCl}_{2}$ (Kanto Chemical) and phosphorus pentoxide (Kanto Chemical) and distilled under a nitrogen atmosphere. Neopentyl diacrylate (NPDA) (Tokyo Chemical Industry, >95\%) was purified by $\mathrm{SiO}_{2}$ column chromatography before use.

\section{Measurements \\ ${ }^{1} \mathrm{H}(400 \mathrm{MHz})$ and ${ }^{13} \mathrm{C}(100 \mathrm{MHz})$ nuclear magnetic resonance (NMR) spectra were measured on a JEOL (Tokyo, Japan) ECX-400 instrument using tetramethylsilane as the internal standard and $\mathrm{CDCl}_{3}$ as the solvent at ambient temperature. Elemental analysis was carried out on a Perkin-Elmer (Waltham, MA, USA) 2400 II CHNS/O analyzer. The UV - vis spectra were recorded using a JASCO (Tokyo, Japan) V-630BIO UV - vis spectrophotometer. Refractive indices $\left(n_{\mathrm{D}}\right)$ and Abbe numbers $\left(v_{\mathrm{D}}\right)$ were measured with an Atago (Tokyo, Japan) DR-M4 digital Abbe refractometer. The X-ray photoelectron spectroscopy (XPS) spectrum was measured with a Kratos (Manchester, UK) AXIS-NOVA instrument. The high-pressure mercury lamp that was used was a HB100A-1 from Sen Lights (Osaka, Japan). Thermogravimetric analysis was performed on a Seiko (Tokyo, Japan) TG/DTA6000 (EXSTER6000) instrument $\left(10^{\circ} \mathrm{C} \mathrm{min}^{-1}, \mathrm{~N}_{2}\right)$. Differential scanning calorimetry measurements were performed on a Seiko DSC-220 instrument under a nitrogen atmosphere $\left(10^{\circ} \mathrm{C} \min ^{-1}\right.$, second heating scan).}

\section{Synthesis of zinc bis $\left(\mathrm{N}, \mathrm{N}\right.$-diallyldithiocarbamate) $\left(\mathrm{Zn}(\mathrm{DADTC})_{2}\right)$} Diallylamine (12 mmol, $1.17 \mathrm{~g}$ ) and carbon disulfide ( $13 \mathrm{mmol}, 0.990 \mathrm{~g})$ were stirred in dioxane $(10 \mathrm{ml})$ at $0{ }^{\circ} \mathrm{C}$ under a nitrogen atmosphere. After the mixture was stirred for $5 \mathrm{~min}$, zinc nitrate hexahydrate $(6 \mathrm{mmol}, 1.78 \mathrm{~g})$ was added. After stirring for $5 \mathrm{~h}$, volatile substances were evaporated off and excess amount of diethyl ether was added to the mixture. The soluble part was collected by filtration, and diethyl ether was evaporated off. Colorless crystals of $\mathrm{Zn}(\mathrm{DADTC})_{2}$ were obtained by recrystallization of the residue with ethanol $($ Yield $=12 \%(0.295 \mathrm{~g}))$. m.p. $=143-145^{\circ} \mathrm{C}$.
${ }^{1} \mathrm{H}-\mathrm{NMR}\left(400 \mathrm{MHz}, \mathrm{CDCl}_{3}\right.$, rt, $\delta$ in p.p.m.): $4.46(8 \mathrm{H}, \mathrm{d}, J=8 \mathrm{~Hz}$, $\left.\mathrm{CH}_{2}=\mathrm{CHCH}_{2}-\right), 5.28-5.32\left(8 \mathrm{H}, \mathrm{m}, \mathrm{CH}_{2}=\mathrm{CHCH}_{2}-\right), 5.88-5.92(4 \mathrm{H}, \mathrm{m}$, $\left.\mathrm{CH}_{2}=\mathrm{CHCH}_{2}-\right) .{ }^{13} \mathrm{C}-\mathrm{NMR}\left(100 \mathrm{MHz}, \mathrm{CDCl}_{3}, \quad\right.$ rt, $\delta$ in p.p.m.): 55.88 $\left(\mathrm{CH}_{2}=\mathrm{CHCH}_{2}-\right), 119.25\left(\mathrm{CH}_{2}=\mathrm{CHCH}_{2}-\right), 130\left(\mathrm{CH}_{2}=\mathrm{CHCH}_{2}-\right), 204.68$ $(C=S)$. Anal. calcd for $\mathrm{C}_{14} \mathrm{H}_{20} \mathrm{~N}_{2} \mathrm{~S}_{4}: \mathrm{C}, 41.01 ; \mathrm{H}, 4.92 ; \mathrm{N}, 6.83 ; \mathrm{S}, 31.29$. Found: C, 41.16; H, 4.88; N, 6.79; S, 31.32.

\section{Synthesis of zinc bis $(\mathrm{N}$-allyl- $\mathrm{N}$-propyldithiocarbamate $)$ $\left(\mathrm{Zn}(\mathrm{APDTC})_{2}\right)$}

Allylpropylamine $^{34}(12 \mathrm{mmol}, 1.19 \mathrm{~g})$ and carbon disulfide $(13 \mathrm{mmol}, 0.990 \mathrm{~g})$ were stirred in ethanol $(10 \mathrm{ml})$ at $0{ }^{\circ} \mathrm{C}$ under a nitrogen atmosphere. After the mixture was stirred for $5 \mathrm{~min}$, zinc nitrate hexahydrate $(6 \mathrm{mmol}, 1.78 \mathrm{~g})$ was added. After stirring for $5 \mathrm{~h}$, the volatile substances were evaporated off and an excess amount of diethyl ether was added to the mixture. The soluble part was collected by filtration, and diethyl ether was evaporated off. Transparent crystals of $\mathrm{Zn}(\mathrm{APDTC})_{2}$ were obtained by the recrystallization of the residue with ethanol (Yield $=19 \%(0.472 \mathrm{~g})$ ). m.p. $=80-81{ }^{\circ} \mathrm{C} .{ }^{1} \mathrm{H}-\mathrm{NMR}(400 \mathrm{MHz}$, $\mathrm{CDCl}_{3}, \mathrm{rt}, \delta$ in p.p.m.): $0.96\left(6 \mathrm{H}, t, J=18.4 \mathrm{~Hz}, \mathrm{CH}_{3} \mathrm{CH}_{2} \mathrm{CH}_{2}-\right), 1.76-1.82$ $\left(4 \mathrm{H}, \mathrm{m}, \mathrm{CH}_{3} \mathrm{CH}_{2} \mathrm{CH}_{2}-\right), 3.73-3.77\left(4 \mathrm{H}, t, J=16 \mathrm{~Hz}, \mathrm{CH}_{3} \mathrm{CH}_{2} \mathrm{CH}_{2}-\right), 4.47$ $\left(4 \mathrm{H}, \mathrm{d}, J=8 \mathrm{~Hz}, \mathrm{CH}_{2}=\mathrm{CHCH}_{2}-\right), 5.28-5.31\left(4 \mathrm{H}, \mathrm{m}, \mathrm{CH}_{2}=\mathrm{CHCH}_{2}-\right)$, 5.87-5.91 (2H, m, $\left.\mathrm{CH}_{2}=\mathrm{CHCH}_{2}-\right) .{ }^{13} \mathrm{C}-\mathrm{NMR}\left(100 \mathrm{MHz}, \mathrm{CDCl}_{3}, \mathrm{rt}, \delta\right.$ in p.p.m.): $11.25\left(\mathrm{CH}_{3} \mathrm{CH}_{2} \mathrm{CH}_{2}-\right), 20.26 \quad\left(\mathrm{CH}_{3} \mathrm{CH}_{2} \mathrm{CH}_{2}-\right), \quad 55.85$ $\left(\mathrm{CH}_{3} \mathrm{CH}_{2} \mathrm{CH}_{2}-\right), 57.11\left(\mathrm{CH}_{2}=\mathrm{CHCH}_{2}-\right), 119.12\left(\mathrm{CH}_{2}=\mathrm{CHCH}_{2}-\right), 130.60$ $\left(\mathrm{CH}_{2}=\mathrm{CHCH}_{2}-\right), 204.68(\mathrm{C}=\mathrm{S})$. Anal. calcd for $\mathrm{C}_{14} \mathrm{H}_{24} \mathrm{~N}_{2} \mathrm{~S}$ : C, 40.61; H, 5.58; N, 6.77; S, 30.98. Found: C, 40.55; H, 5.90; N, 6.80; S, 31.17.

\section{Preparation of films (typical procedure)}

$\mathrm{Zn}(\mathrm{DADTC})_{2}$ (2 mmol, $0.820 \mathrm{~g}$ ) and Irgacure 651 ( $3 \mathrm{~mol} \%$ to the monomers, $100 \mathrm{mg})$ were dissolved in NPDA $(6 \mathrm{mmol}, 1.27 \mathrm{~g})$ with heating. After the mixture became homogeneous, PTM $(5 \mathrm{mmol}, 2.44 \mathrm{~g})$ was mixed in. The mixture was poured into a stainless steel mold ( $w / 1 / d=10 \mathrm{~mm} / 46 \mathrm{~mm} / 1 \mathrm{~mm}$ ) and cured by UV irradiation for $30 \mathrm{~min}$. The gel fraction of the film $(0.253 \mathrm{~g})$ was determined by Soxhlet extraction with tetrahydrofuran (THF) for $7 \mathrm{~h}$ under reflux followed by drying under reduced pressure $(0.247 \mathrm{~g}, 97.6 \%)$.

\section{RESULTS AND DISCUSSION}

\section{Synthesis and characterization of monomers}

$\mathrm{Zn}(\mathrm{ADTC})_{2}$ monomers were prepared using a previously established method for zinc alkyldithiocarbamates, as shown in Scheme 1 and Supplementary Figures S1-S4. ${ }^{24} \mathrm{Zn}(\mathrm{DADTC})_{2}$ and $\mathrm{Zn}(\mathrm{APDTC})_{2}$ were obtained as white crystals via a simple one-pot reaction. The monomers were stable enough to be tolerant of treatments with $1 \mathrm{~m}$ aqueous $\mathrm{HCl}$ and $1 \mathrm{M}$ aqueous $\mathrm{NaOH}$. The $n_{\mathrm{D}}$ values of $\mathrm{Zn}$ $(\mathrm{DADTC})_{2}$ and $\mathrm{Zn}(\mathrm{APDTC})_{2}$ were estimated to be 1.64 and 1.62 , respectively, by extrapolating from their $n_{\mathrm{D}}$ values at various concentrations in $\mathrm{N}, \mathrm{N}$-dimethylformamide (DMF) (Supplementary Figure S5).

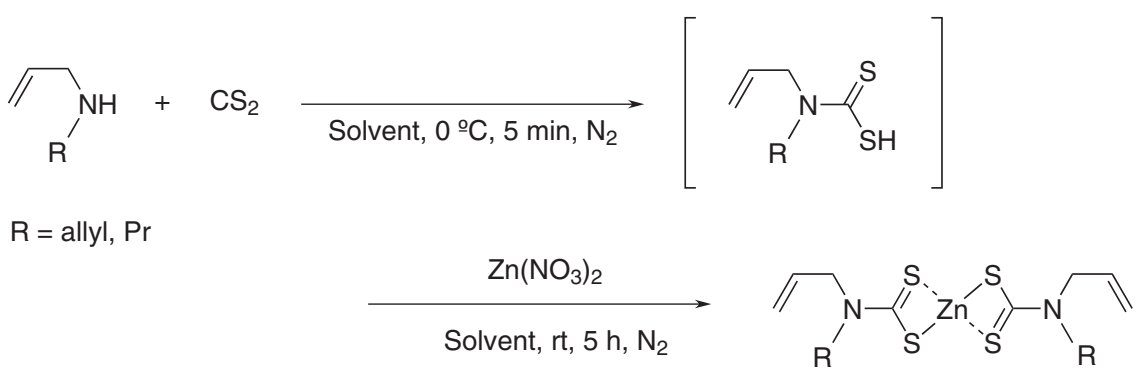

Scheme 1 Synthesis of the $\mathrm{Zn}(\mathrm{ADTC})_{2}$ derivatives. 


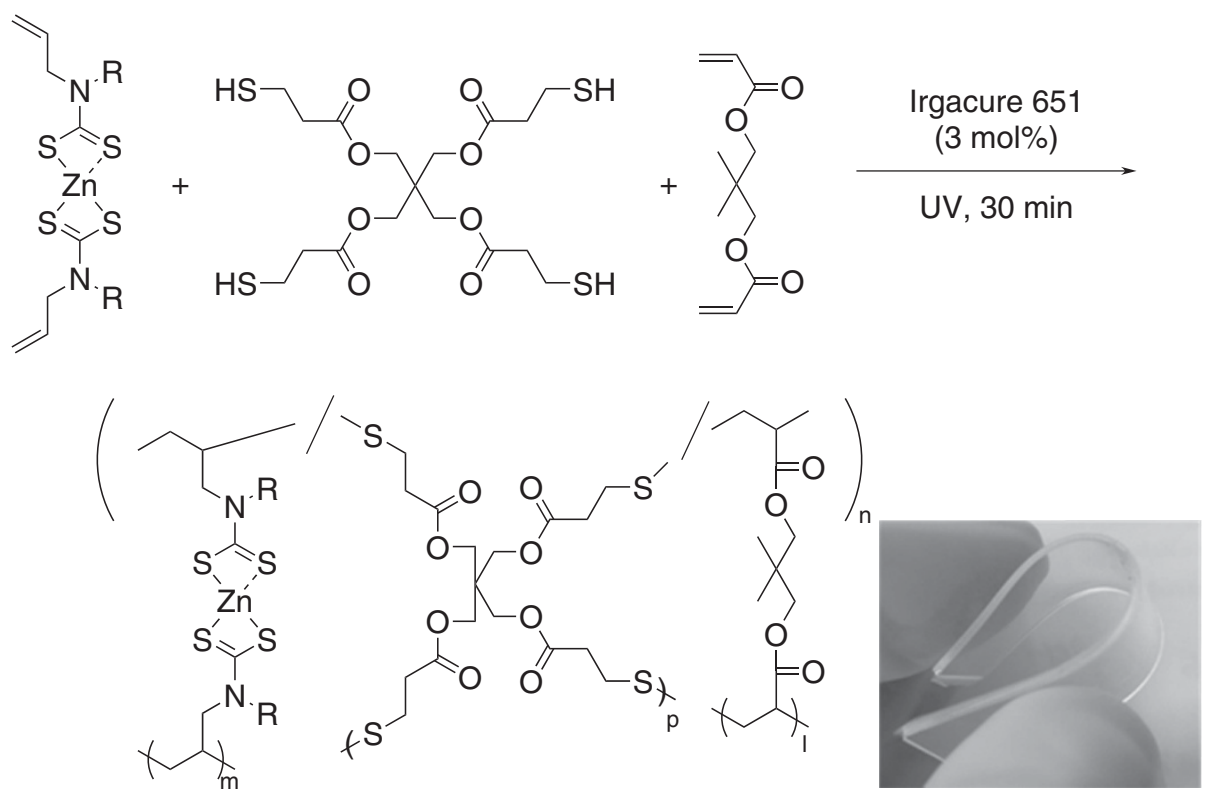

Scheme 2 Thiol-ene reaction of the $\mathrm{Zn}(\mathrm{ADTC})_{2}$ derivatives. The photograph shows a flexible film prepared using $18 \mathrm{wt} \%$ of $\mathrm{Zn}(\mathrm{DADTC})_{2}$. A full color version of this figure is available at Polymer Journal online.

\section{Synthesis and characterization of films}

We first tried to use $\mathrm{Zn}(\mathrm{ADTC})_{2}$ derivatives in a thiol-ene reaction with PTM, but they were insoluble. Therefore, we added NPDA and effected curing in the presence of Irgacure 651 (3 mol\%) under air and UV irradiation for $30 \mathrm{~min}$ (Scheme 2). This three-component curing produced flexible and transparent films. Colorless films were obtained using 9-18 wt $\%$ and $10-30 \mathrm{wt} \% \mathrm{Zn}(\mathrm{DADTC})_{2}$ and $\mathrm{Zn}$ $(\mathrm{APDTC})_{2}$, respectively. All of the films were insoluble in common solvents, although the gel fractions after Soxhlet extraction with THF were very high (Figure 1); 9 and $27 \mathrm{wt} \% \mathrm{Zn}(\mathrm{DADTC})_{2}$ gave fractions of 98 and 95\%, respectively. This good solvent resistance can be ascribed to the efficient cross-linking of the four polymerizable moieties in the two diallyl groups. However, the gel fractions of the $\mathrm{Zn}(\mathrm{APDTC})_{2}$ films decreased as the feed ratio of the zinc monomer increased. The water absorbency of the films prepared using $18 \mathrm{wt} \%$ $\mathrm{Zn}(\mathrm{DADTC})_{2}$ and $30 \mathrm{wt} \% \mathrm{Zn}(\mathrm{APDTC})_{2}$ was below $2 \%$, supporting the non-ionic character of the zinc dithiocarbamate moieties (Supplementary Information).

The structures of the soluble portions were analyzed by ${ }^{1} \mathrm{H}-\mathrm{NMR}$ spectroscopy (Supplementary Figures S7 and S8). There were no double bond signals corresponding to $\mathrm{Zn}(\mathrm{ADTC})_{2}$ derivatives or NPDA, which suggests the excellent conversion of the vinyl moieties. The structure of the flexible products resulting from the reactions of $\mathrm{Zn}(\mathrm{DADTC})_{2}(18 \mathrm{wt} \%)$ and $\mathrm{Zn}(\mathrm{APDTC})_{2}(30 \mathrm{wt} \%)$ were analyzed by Fourier transfer infrared (FT-IR) spectroscopy (Figure 2; Supplementary Figure S9) and XPS (Supplementary Figure S10). Again, the C $=\mathrm{C}$ and $\mathrm{C}=\mathrm{C}-\mathrm{H}\left(3080 \mathrm{~cm}^{-1}\right)$ signals from the $\mathrm{Zn}(\mathrm{ADTC})_{2}$ derivatives $\left(1639 \mathrm{~cm}^{-1}\right)$ and NPDA $\left(1635 \mathrm{~cm}^{-1}\right)$ had completely disappeared. The presence of the characteristic $\mathrm{Zn}$ dithiocarbamate groups originating from the $\mathrm{Zn}(\mathrm{ADTC})_{2}$ derivatives was confirmed by an infrared signal assignable to a $\mathrm{C}=\mathrm{S}$ stretching vibration $\left(1488 \mathrm{~cm}^{-1}\right)$. The chemical shifts of the Zn XPS signals were identical for both the monomers and the films. This suggests that the zinc dithiocarbamate core was retained throughout the polymerization.

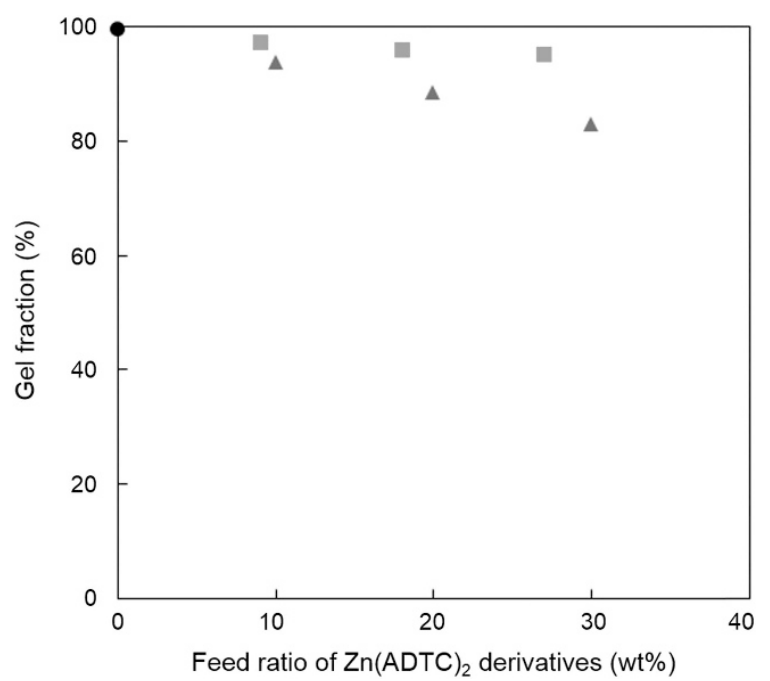

Figure 1 Relationship between the gel fraction and feed ratios of $\mathrm{Zn}(\mathrm{DADTC})_{2}$ (red squares) and $\mathrm{Zn}(\mathrm{APDTC})_{2}$ (blue triangles). A full color version of this figure is available at Polymer Journal online.

\section{Properties of films}

The thermal properties of the films were evaluated by thermogravimetric analysis and differential scanning calorimetry (Table 1). The temperatures of $5 \%$ weight loss $\left(T_{\mathrm{d} 5} \mathrm{~s}\right)$ unfortunately decreased as the zinc monomer content increased, but they were generally higher than $200^{\circ} \mathrm{C}$. The $T_{\mathrm{d} 5} \mathrm{~s}$ of the films prepared using $\mathrm{Zn}(\mathrm{DADTC})_{2}$ were higher than those using $\mathrm{Zn}(\mathrm{APDTC})_{2}$, and the robustness can be ascribed to the four polymerizable groups leading to a higher cross-linking efficiency. The low glass transition temperatures $\left(T_{\mathrm{g}} \mathrm{s}\right)$ agree with the flexibility of the films. $\mathrm{Zn}(\mathrm{DADTC})_{2}$ exhibited a slightly increased $T_{\mathrm{g}}$ owing to the stiff cyclopolymerized unit and/or the higher cross-linking efficiency, whereas $\mathrm{Zn}(\mathrm{APDTC})_{2}$ 

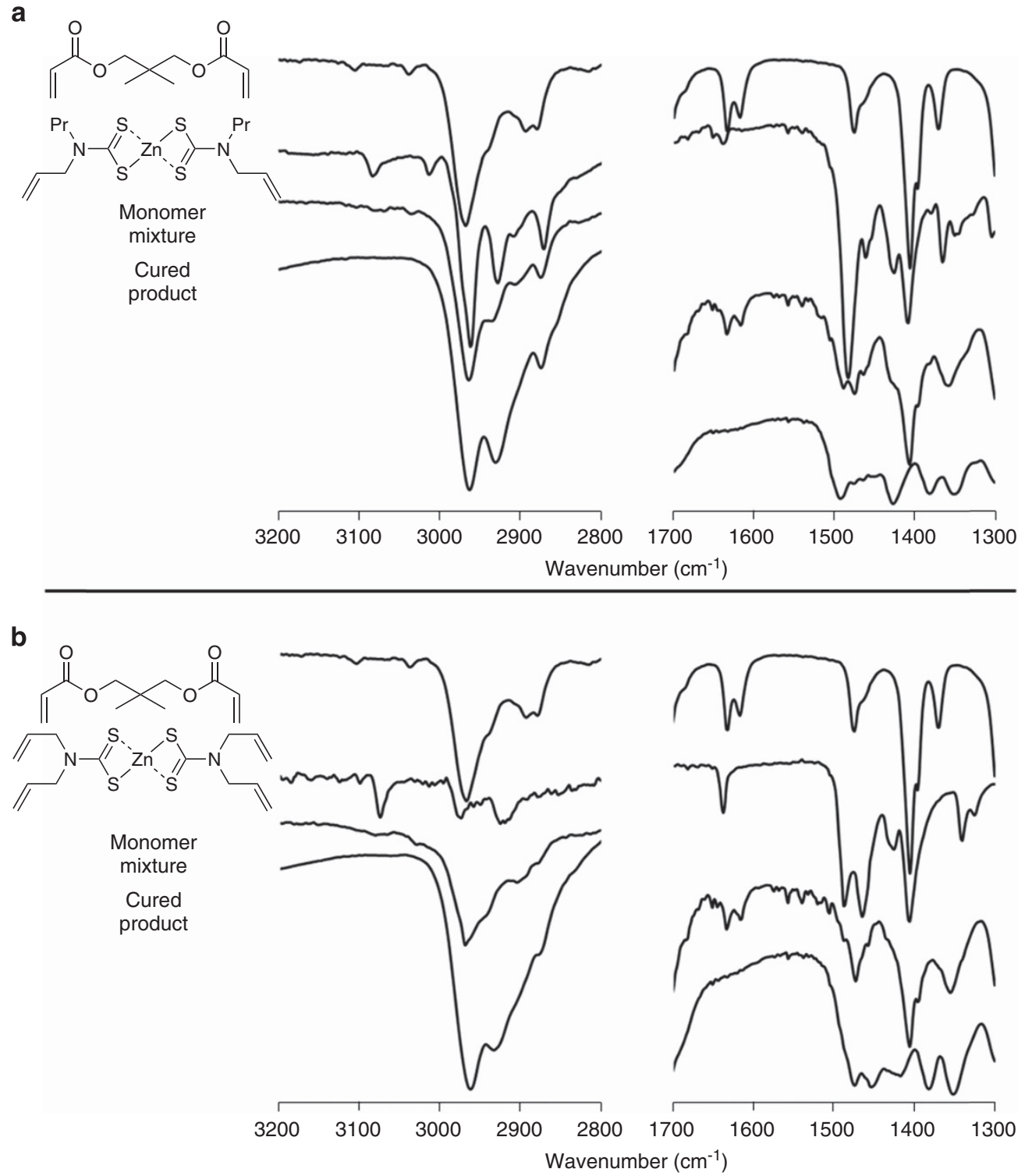

Figure 2 FT-IR spectra (3200-2800 and 1700-1300 $\mathrm{cm}^{-1}$ ) of monomers, monomer mixtures and cured products obtained using (a) Zn(APDTC) 2 (30 wt\%) and (b) $\mathrm{Zn}(\mathrm{DADTC})_{2}(18 \mathrm{wt} \%)$.

Table $1 T_{\mathrm{d} 5}$ and $T_{\mathrm{g}}$ of films prepared from $\mathrm{Zn}(\mathrm{DADTC})_{2}$ and $\mathrm{Zn}(\mathrm{APDTC})_{2}$

\begin{tabular}{lccc}
\hline Zinc monomer & Content $(w t \%)$ & $\mathrm{T}_{d 5}\left({ }^{\circ} \mathrm{C}\right)^{\mathrm{a}}$ & $\mathrm{T}_{\mathrm{g}}\left({ }^{\circ} \mathrm{C}\right)^{b}$ \\
\hline None & - & 346 & -10 \\
Zn(DADTC) & 2 & 268 & -8 \\
& 9 & 247 & -5 \\
Zn(APDTC $)_{2}$ & 18 & 209 & -17 \\
& 10 & 203 & -12 \\
& 20 & 181 & -18 \\
\hline
\end{tabular}

${ }^{a}$ Determined by thermogravimetric analysis $\left(10^{\circ} \mathrm{C} \mathrm{min}^{-1}, \mathrm{~N}_{2}\right)$.

${ }^{b}$ Determined by differential scanning calorimetry $\left(10^{\circ} \mathrm{C} \mathrm{min}^{-1}\right.$, second heating scan).

exhibited a lower $T_{\mathrm{g}}$ because of the flexible propyl and reacted propylene moieties.

The transparency of the cured products was evaluated by UV-vis spectroscopy. The specimens were prepared by curing the polymerization mixtures after drop-coating on glass substrates. The transmission spectra of the films are shown in Figure 3. Overall, the transmittance in the visible region exceeded $79 \%$ in all cases. However, it significantly dropped in the UV region at $\sim 370 \mathrm{~nm}$, likely as a result of incorporating the $\mathrm{Zn}(\mathrm{ADTC})_{2}$ derivatives. This slight red-shift in transmittance originated from the absorption of the zinc dithiocarbamate core (Supplementary Figure S6). The film prepared with $18 \mathrm{wt} \% \mathrm{Zn}(\mathrm{DADTC})_{2}$ was transparent, but that prepared with $27 \mathrm{wt} \% \mathrm{Zn}(\mathrm{DADTC})_{2}$ was pale yellow. However, the film prepared with $30 \mathrm{wt} \% \mathrm{Zn}(\mathrm{APDTC})_{2}$ was transparent. This difference originated from the preheating process required for $\mathrm{Zn}(\mathrm{DADTC})_{2}$ owing to its solubility. Although $\mathrm{Zn}(\mathrm{APDTC})_{2}$ is soluble in the mixture of PTM and NPDA at room temperature owing to its flexible propyl groups and unsymmetrical structure, the symmetrical $\mathrm{Zn}(\text { DADTC })_{2}$ required higher temperatures of $\sim 80^{\circ} \mathrm{C}$ to dissolve, which resulted in yellowing.

Next, we evaluated the $n_{\mathrm{D}}$ values and Abbe numbers $\left(v_{\mathrm{D}}\right)$ of the produced films (Figure 4). Overall, the $n_{\mathrm{D}}$ values linearly increased 

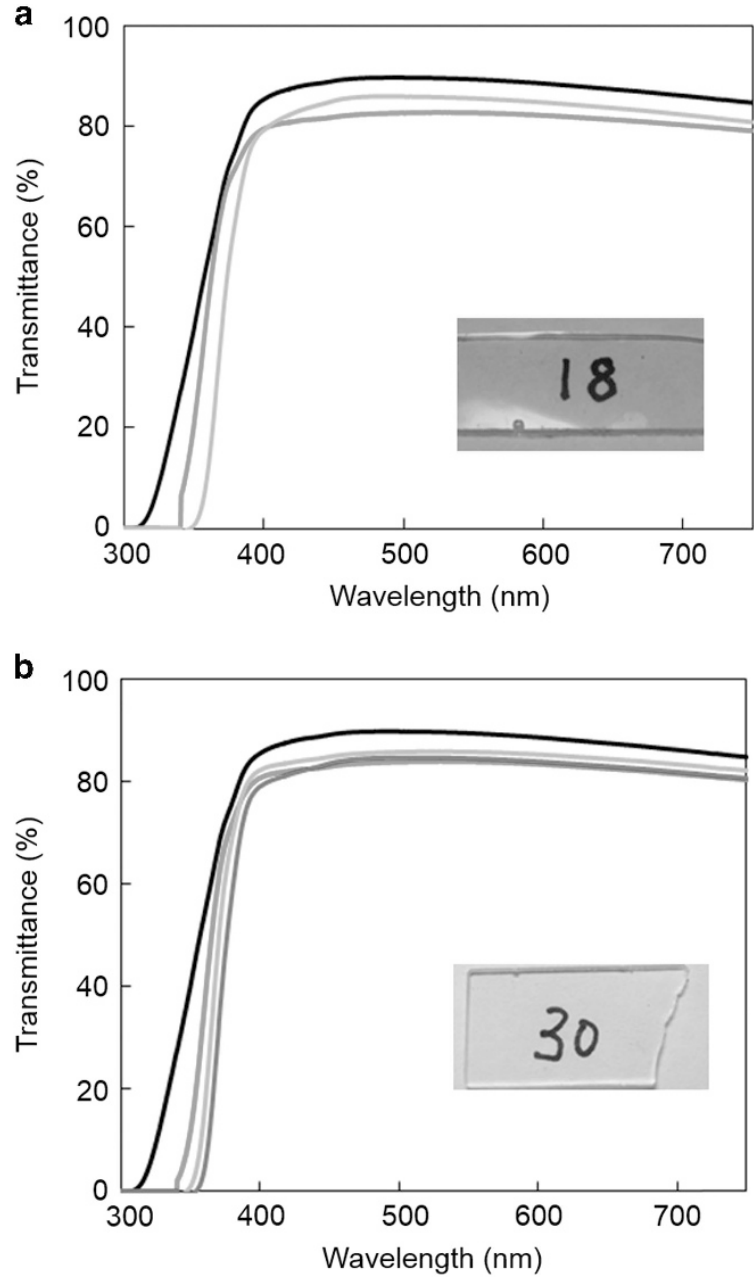

Figure 3 Transmission spectra of films prepared by curing (a) $\mathrm{Zn}(\text { DADTC) })_{2}$ (black line, $0 \mathrm{wt} \%$; red line, $9 \mathrm{wt} \%$; orange line, $18 \mathrm{wt} \%$ ) and (b) $\mathrm{Zn}$ $\left(\right.$ APDTC) ${ }_{2}$ (black line, $0 \mathrm{wt} \%$; red line, $10 \mathrm{wt} \%$; orange line, $20 \mathrm{wt} \%$; blue line, 30 wt\%) with PTM and NPDA $\left.\left([S H]_{0} /\left[\mathrm{CH}_{2}=\mathrm{CH}\right]_{0}=1 / 1\right]\right)$. The inset images are photographs of the films prepared by the curing of (a) $\mathrm{Zn}$ $(\text { DADTC })_{2}$, PTM and NPDA $(\mathrm{w} / \mathrm{w} / \mathrm{w}=30 / 46 / 24)$ and (b) $\mathrm{Zn}(\text { APDTC })_{2}$, PTM and NPDA $(\mathrm{w} / \mathrm{w} / \mathrm{w}=18 / 54 / 28)$. NPDA, neopentyl diacrylate, PTM, pentaerythritol tetrakis(3-mercaptopropionate). A full color version of this figure is available at Polymer Journal online.

with the monomer concentration. Most notably, the $n_{\mathrm{D}}$ values of the films prepared using $18 \mathrm{wt} \% \mathrm{Zn}(\mathrm{DADTC})_{2}$ and $30 \mathrm{wt} \% \mathrm{Zn}(\mathrm{APDTC})_{2}$ were 1.563 and 1.569 , respectively, which are higher than those of the film prepared from PTM and NPDA in the absence of zinc monomers. However, the $v_{\mathrm{D}}$ decreased slightly with the increasing feed ratio, possibly because of the high refractive indices of the zinc monomers. The $n_{\mathrm{D}}$ values of the units originating from $\mathrm{Zn}(\mathrm{DADTC})_{2}$ and $\mathrm{Zn}(\mathrm{APDTC})_{2}$ were calculated to be 1.713 and 1.666 , respectively (Supplementary Figures S11 and S12), based on the relationships of the $n_{\mathrm{D}}$ values and feed ratios. The higher $n_{\mathrm{D}}$ observed for $\mathrm{Zn}(\mathrm{DADTC})_{2}$ can be ascribed to its four polymerizable groups, leading to a higher cross-linking efficiency and thereby denser films. We estimated the direction dependence of the refractive indices toward polarization for the films prepared using $18 \mathrm{Zn}(\mathrm{DADTC})_{2}$ and $30 \mathrm{wt} \% \mathrm{Zn}(\mathrm{APDTC})_{2}$. The differences in the parallel and perpendicular $n_{\mathrm{D}} \mathrm{S}$ were 0.002 , which is within the error of the
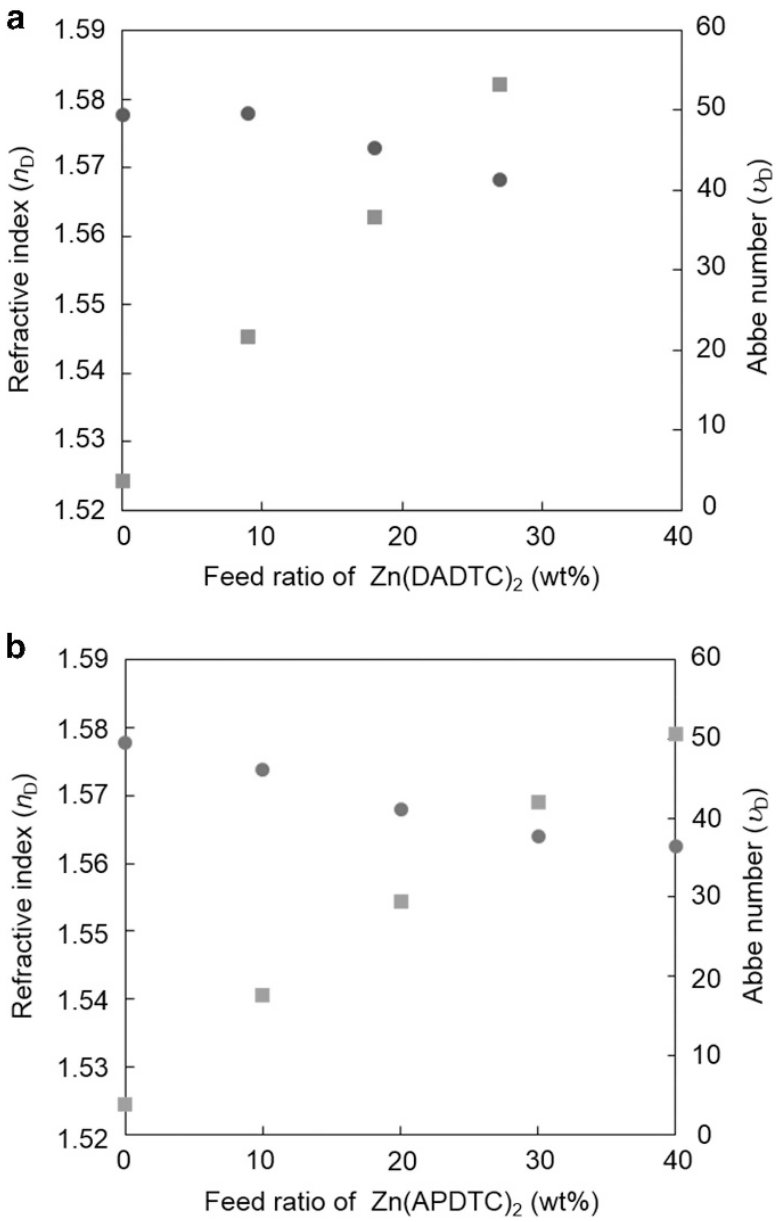

Figure $4 n_{\mathrm{D}}$ and $v_{\mathrm{D}}$ values with respect to feed ratio for films of (a) $\mathrm{Zn}$ $(\text { DADTC })_{2}$ (pink squares, $n_{\mathrm{D}}$; green circles, $v_{\mathrm{D}}$ ) and (b) Zn(APDTC) ${ }_{2}$ (red squares, $n_{\mathrm{D}}$; blue circles, $v_{\mathrm{D}}$ ). A full color version of this figure is available at Polymer Journal online.

measurements, which supports the low birefringence owing to the amorphous natures.

\section{CONCLUSIONS}

This paper reported the synthesis and thiol-ene curing of $\mathrm{Zn}(\mathrm{ADTC})_{2}$ derivatives as a new class of organic-inorganic hybrid monomers for flexible and refractive materials. Two $\mathrm{Zn}(\mathrm{ADTC})_{2}$ derivatives were obtained by a simple one-pot reaction of allylamines, carbon disulfide and zinc salt. The thiol-ene reaction of the synthesized $\mathrm{Zn}(\mathrm{ADTC})_{2}$ derivative monomers with an inexpensive and common thiol, and alkene produced transparent, flexible and refractive films. $\mathrm{Zn}(\mathrm{DADTC})_{2}$, a species bearing four polymerizable groups, attained higher $n_{\mathrm{D}}$ and $\mathrm{v}_{\mathrm{D}}$ values, where its low solubility limited the possible range of feed ratios. By contrast, $\mathrm{Zn}$ (APDTC) $)_{2}$ allowed for higher feed ratios, given its higher solubility. These hybrid monomers are accessible and offer structurally tunable refractive monomer systems for UV curing. Further investigations of applicable polymerization methods will continue to search for organic-inorganic materials with excellent optical properties for electronic and optical devices.

\section{CONFLICT OF INTEREST}

The author declares no conflict of interest. 


\section{ACKNOWLEDGEMENTS}

Elemental analysis was performed by Mr. Takeyoshi Takahashi of Yamagata University. XPS analysis was performed by Dr. Daisuke Nagai (Department of Chemistry and Chemical Biology, Graduate School of Engineering, Gunma University). We appreciate the financial supports from JSPS KAKENHI Grant Number 25410208 and JST A-STEP (AS221Z01415D).

1 Fernandes, J. N., Akbarzadeh, J., Peterlik, H. \& Giannelis, P. E. Synthesis and properties of highly dispersed ionic silica-poly(ethylene oxide) nanohybrids. ACS Nano 7, 1265-1271 (2013).

2 Qi, L., Sehgal, A., Castaing, C. J., Chapel, P. J., Fresnais, J., Berret, F. J. \& Cousin, F. Redispersible hybrid nanopowders: cerium oxide nanoparticle complexes with phosphonated-PEG oligomers. ACS Nano 2, 879-888 (2008).

3 Althues, H., Henle, J. \& Kaskel, S. Functional inorganic nanofillers for transparent polymers. Chem. Soc. Rev. 36, 1454-1465 (2007).

4 Beecroft, L. L. \& Ober, C. Nanocomposite materials for optical applications. Chem. Mater. 9, 1302-1317 (1997).

5 Park, K. S., Kang, K. B., Shin, W. J., Joo, W. C., Moon, J., Cho, H. D., Yu, B., Chu, Y. H. \& Lee, I. J. Triethylene glycol-titanium oxide hydrate hybrid films with high refractive index and surface evenness. J. Mater. Chem. C 2, 4468-4475 (2014).

6 Maliakal, A., Katz, H., Cotts, M. P., Subramoney, S. \& Mirau, P. Inorganic oxide core, polymer shell nanocomposite as a high $\mathrm{K}$ gate dielectric for flexible electronics applications. J. Am. Chem. Soc. 127, 14655-14662 (2005).

7 Lu, C., Guan, C., Liu, Y., Cheng, Y. \& Yang, B. PbS/polymer nanocomposite optical materials with high refractive index. Chem. Mater. 17, 2448-2454 (2005).

8 Bhagat, D. S., Chatterjee, J., Chen, B. \& Stiegman, E. A. High refractive index polymers based on thiol-ene cross-linking using polarizable inorganic/organic monomers. Macromolecules 45, 1174-1181 (2012).

9 Qin, D., Yan, E., Yu, J., Zhang, W., Liu, B. \& Yang, X. Synthesis of polymer/zirconium hydroxide core-shell microspheres and the hollow porous zirconium oxide microspheres. Mater. Chem. Phys. 136, 688-697 (2012).

10 Jeon, Y. I. \& Baek, B. J. Nanocomposites derived from polymers and inorganic nanoparticles. Materials 3, 3654-3674 (2010).

11 Zhao, Y., Wang, F., Fu, Q. \& Shi, W. Synthesis and characterization of ZnS/hyperbranched polyester nanocomposite and its optical properties. Polymer 48 2853-2859 (2007).

12 Nakayama, N. \& Hayashi, T. Preparation and characterization of $\mathrm{TiO}_{2}-\mathrm{ZrO}_{2}$ and thiolacrylate resin nanocomposites with high refractive index via UV-induced crosslinking polymerization. Compos. Part A 38, 1996-2004 (2007).

13 Goncalves, H. R., Schreiner, H. W. \& Leite, R. E. Synthesis of $\mathrm{TiO}_{2}$ nanocrystals with a high affinity for amine organic compounds. Langmuir 26, 11657-11662 (2010).

14 Webel, W., Caseri, W., Suter, U. W., Kiss, H. \& Wehrli, E. Preparation of polyme nanocomposites with "ultrahigh" refractive index. Adv. Technol. 2, 75-80 (1991).

15 Zimmermann, L., Weibel, M., Caseri, W. \& Suter, U. W. Scanning force microscopy investigation of poly(ethylene terephthalate) modified by argon plasma treatment. J. Mater. Chem. 8, 1735-1742 (1993).

16 Dieudonné, X., Vallé, K. \& Belleville, P. Towards new levels for stacking of sol-gel functional coatings. Opt. Express 19, 16356-16364 (2011).

17 Lu, C. \& Yang, B. High refractive index organic-inorganic nanocomposites: design, synthesis and application. J. Mater. Chem. 19, 2884-2901 (2009).

18 Wang, F., Luo, Z., Qing, S., Qiu, Q. \& Li, R. Sol-gel derived titania hybrid thin films with high refractive index. J. Alloys Compd. 486, 521-526 (2009).

19 Parlak, O. \& Demir, M. M. Toward transparent nanocomposites based on polystyrene matrix and PMMA-grafted $\mathrm{CeO}_{2}$ nanoparticles. ACS Appl. Mater. Interfaces 3, 4306-4314 (2011)

20 Otsuka, T. \& Chujo, Y. Poly(methyl methacrylate) (PMMA)-based hybrid materials with reactive zirconium oxide nanocrystals. Polym. J. 42, 58-65 (2010)

21 Lee, W. S., Park, W. J., Park, H. C. \& Kim, J. H. Enhanced optical properties and thermal stability of optically clear adhesives. Int. J. Adhes. Adhes. 50, 93-95 (2014).
22 Jaisankar, N. S., Nelson, J. D., Kumar, R. \& Mandal, B. A. Ionomer covalent functionalization of single-walled carbon nanotubes by radical polymerization of zirconium acrylate. AlChE J. 60, 820-828 (2014).

23 Sadeghi, T. M. S. Synthesis, characterization \& thermal stability study of polyelectrolytes (some transition metal salts). Iran Polym. J. 14, 657-666 (2005).

24 Marimuthu, G., Ramalingam, K. \& Rizzoli, C. Synthesis, spectral, thermal and BVS investigations on $\mathrm{ZnS} 4 \mathrm{~N} \wedge \mathrm{N} / \mathrm{N}$ coordination environment: single crystal X-ray structures of bis(dibenzyldithiocarbamato)( $\left.\mathrm{N}^{\wedge} \mathrm{N}\right) \mathrm{Zinc}(\mathrm{II})$ complexes $\left(\mathrm{N}^{\wedge} \mathrm{N}=1,10\right.$-phenanthroline, tetramethylethylenediamine and 4,4'-bipyridine). Polyhedron 29, 1555-1560 (2010)

25 Meibner, A., Haehnel, W. \& Vahrenkamp, H. On the role of structural zinc in bis (cysteinyl) protein sequences. Chem. Eur. J. 3, 261-267 (1997).

26 Burth, R. \& Vahrenkamp, H. Zinc thiolate complexes with chelating nitrogen ligands. Inorg. Chim. Acta 282, 193-199 (1998).

27 Prakasam, A. B., Lahtinen, M., Peuronen, A., Muru-ganandham, M., Kolehmainen, E., Haapaniemi, E. \& Sillan-pää, M. Phase selective synthesis of ZnS nanoparticles from structurally new dithiocarbamate precursor. Mater. Lett. 144, 19-21 (2015).

28 Nieuwenhuizen, J. P., Ehlers, W. A., Haasnoot, G. J., Janse, R. S., Reedijk, J. \& Baerends, J. J. The Mechanism of Zinc(II)-Dithiocarbamate-accelerated vulcanization uncovered; theoretical and experimental evidence. J. Am. Chem. Soc. 121, 163-168 (1998).

29 Okutu, R., Ando, S. \& Ueda, M. Sulfur-containing poly(meth)acrylates with high refractive indices and high Abbe's numbers. Chem. Mater. 20, 4017-4023 (2008).

30 Chan, J. W., Zhou, H. \& Hoyle, C. E. Photopolymerization of thiol-alkynes: polysulfide networks. Chem. Mater. 21, 1579-1585 (2009).

31 Kudo, H., Inoue, H., Inagaki, T. \& Nishikubo, T. Synthesis and refractive-index properties of star-shaped polysulfides radiating from calixarenes. Macromolecules $\mathbf{4 2}$, 1051-1057 (2009).

32 Suzuki, Y., Higashihara, T., Ando, S. \& Ueda, M. Synthesis of high refractive index poly (thioether sulfone) with high Abbe's number derived from 2,5-is(sulfanylmethyl)-I,4dithiane. Polym. J. 41, 860-865 (2009).

33 Ochiai, B. \& Konta, H. Organic-sulfur-zinc hybrid nanoparticle for optical applications synthesized via polycondensation of trithiol and $\mathrm{Zn}(\mathrm{OAc})_{2}$. Nanoscale Res. Lett. 8, 373 (2013).

34 Hoyle, E. C., Lee, Y. T. \& Roper, T. Thiol-enes: chemistry of the past with promise for the future. J. Polym. Sci. A Polym. Chem. 42, 5301-5338 (2004).

35 Lowe, B. A., Hoyle, E. C., Zhou, H. \& Chan, W. J. Photopolymerization of thiol-alkynes: polysulfide networks. Chem. Mater. 21, 1579-1585 (2009).

36 Fairbanks, D. B., Scott, F. T., Kloxin, J. C., Anseth, S. K. \& Bowman, N. C. Thiol-Yne photopolymerizations: novel mechanism, kinetics, and step-growth formation of highly cross-linked networks. Macromolecules 42, 211-217 (2009).

37 Hoyle, E. C., Lowe, B. A. \& Bowman, N. C. Thiol-click chemistry: a multifaceted toolbox for small molecule and polymer synthesis. Chem. Soc. Rev. 39, 1355-1387 (2010).

38 Park, K. S., Jung, J. J., Kim, T. J., Kim, M., Moon, J., Lee, I. J., Chu, Y. H., Kim, W. D., Kyung, U. K. \& Park, S. Photocrosslinkable liquid prepolymers for flexible waveguide display applications. J. Mater. Chem. C 1, 2983-2989 (2013).

39 Yun, S., Park, S., Park, B., Kim, Y., Park, K. S., Nam, S. \& Kyung, U. K. Polymer-waveguide-based flexible tactile sensor array for dynamic response. Adv. Mater. 26, 4474-4480 (2014).

40 Kumpfmueller, J., Stadlmann, K., Li, Z., Satzinger, V., Stampfl, J. \& Liska, R. Two-photon-induced thiol-ene polymerization as a fabrication tool for flexible optical waveguides. Design. Monom. Polym. 17, 390-400 (2014).

41 Ware, T., Simon, D., Hearon, K., Liu, C., Shah, S., Reeder, J., Khodaparast, N., Kilgard, P. M., Maitland, J. D., Rennaker, L. R. \& Voit, E. W. Three-dimensional flexible electronics enabled by shape memory polymer substrates for responsive neural interfaces. Macromol. Mater. Eng. 297, 1193-1202 (2012).

42 Panayides, L. J., Pathak, R., Panagitopoulos, H., Fernandes, A. M., Koning, B. C. \& Otterlo, L. A. W. The synthesis of 2-benzazonines using ring-closing methathesis as a key step. Tetrahedron 63, 4737-4747 (2007).

43 Priyadarshi, A., Shimin, L., Mhaisalkar, G. S., Rajoo, R., Wong, H. E., Kripesh, V. \& Namdas, B. E. Characterization of optical properties of acrylate based adhesives exposed to different temperature conditions. J. Appl. Polym. Sci. 98, 950-956 (2005).

Supplementary Information accompanies the paper on Polymer Journal website (http://www.nature.com/pj) 